\title{
Doctors' advice to overweight patients concerning healthy lifestyles
}

\author{
Mikael Rahmqvist
}

\begin{abstract}
Background: The physician has an important role that involves informing patients about the benefits of a healthy lifestyle. Objective: The aim was to estimate the proportion of patients who received advice about exercise and/or eating habits in primary health care (PHC) and hospital health care (HHC) in 1991 and 1995. A further aim was to explore the patient characteristics in the group that was given advice.

Design: Subjects were 4890 respondents to a mail-distributed questionnaire who had paid at least one visit to a doctor in PHC or $\mathrm{HHC}$ within the last 12 months.

Results: In PHC about 20\% of the overweight patients received advice in 1991 and 1995, while in HHC the percentage receiving advice increased from $19 \%$ to $28 \%$. Patients background characteristics could not explain this difference in trends. Male patients received more advice in both PHC and HHC, and this could not be explained by factors such as education, health or lifestyle factors, e.g. exercise and smoking.

Conclusion: The results suggest that there is room for more doctors' advice about eating habits and exercise, especially for female patients and patients in primary health care.
\end{abstract}

Keywords: Doctors' advice, health promotion, lifestyles, overweight.

Received: 25 April, 2001. Revised: 30 November, 2002. Accepted: 9 January, 2002

\section{Introduction}

Overweight is associated with an increased risk for a number of diseases and disabilities $(1,2)$. Obesity is associated with an increased risk for over 45 different disorders (3). Many benefits can be derived from curbing or reducing the prevalence of overweight in the population. Quality of life is strongly associated with personal weight, and it has been suggested that individuals of normal weight suffer from less psychological stress than those who are obese (4). Life years can be saved if the prevalence of obesity is curbed or reduced (5). There are also large potential savings in terms of direct and indirect costs $(5,6)$. Owing to the increasing prevalence of obesity in Sweden as well as in most other Western societies $(7,8)$ and the accelerating trend towards increased obesity in several age groups (9), there is an urgent need for a broad approach in dealing with these problems.

The physician has an important role here involving ongoing discussions with patients about healthy lifestyles (10). A representative sample of Swedish doctors confirmed that they considered health promotion to be an important part of their professional activities (11). Of 1700 doctors, 27\% totally agreed and $60 \%$ partially agreed that the most important action they can take to keep a patient healthy is to "try to influence the patient's lifestyle". The doctor's prominent position in the field of prevention is of great interest, and the present study is an attempt to quantify such actions with patients' self-reported data.

The aim of this study was to investigate how frequently doctors in primary health care (PHC) and hospital health care (HHC) gave advice to overweight patients about exercise and healthy eating habits and if the advice affected the patient's lifestyle. The primary question was whether the increased prevalence of overweight during the period under study was accompanied by more frequent advice from doctors about related lifestyles. Another question concerned whether there were any differences in patient characteristics in the group that was given advice about healthy lifestyles between PHC and HHC.

\section{Material and methods}

\section{Design and data collection}

A repeated cross-sectional survey about health and health care was used in this paper. The data collected in 1991 constituted the baseline with which 
the data collected in 1995 were compared. The total sample population, aged 16-74 years, included 284000 people. About 6600 people were randomly selected from this total population register in 1991, and 7300 were randomly selected in 1995. The sample can be considered as representative of the population of the county of Östergötland.

The response rates for complete forms were very similar in the two surveys. The male population had a $64 \%$ response rate for both years, which is significantly lower than the $72 \%$ response rate for females. There were no differences in response rates between the two years. The overall response rate each year was around $68 \%$.

The patients were asked whether the doctor had given them any advice about exercise or eating habits at their last visit to $\mathrm{PHC}$ or $\mathrm{HHC}$ within the past 12 months. The question was asked for primary care and hospital settings, respectively.

\section{Group classification}

All patients included in the study reported their weight and height in the questionnaire, and body mass index (BMI) was then calculated as weight $(\mathrm{kg}) /$ height $\left(\mathrm{m}^{2}\right)$. A BMI over 25 for men and over 24 for women is here considered as overweight. A BMI over 30 for men and over 29 for women is considered as obesity. This classification of relative weight groups is close to the World Health Organization (WHO) classification that was used by the Swedish National board of Health and Welfare up to 1997 (with the difference for women where a BMI $>23.8$ was considered as overweight and a BMI $>28.6$ indicated obesity) (12). In later studies the WHO classification has been changed so that the same cut-off points are used for both men and women, using the old classification for men.

The respondents' self-reported overall health status was categorized into two groups. Four alternatives were given to describe their general health status within the past 12 months. One group of respondents described their status as "completely healthy" or "quite healthy", and the other group reported their overall health within the past 12 months as "quite ill" or "very ill". The latter group will be referred to as the group with ill or poor health, and the former as the group with good health status.

\section{Statistical methods}

All data analyses, including logistic regression, odds ratio calculations and $\chi^{2}$ testing, were done with the statistical package SPSS, Version 7.5.

\section{Results}

In the two surveys, a total of 4890 respondents had paid at least one visit to a doctor within the past 12 months. About $30 \%$ of the patients had made a visit to both PHC and HHC. This means that about one-third of all the respondents had paid a visit to a doctor in PHC and one in four had visited a doctor in HHC.

The patient populations were similar over the years with respect to age and gender distribution (Table 1). Men constituted $40-44 \%$ of the population within each health-care form, and the mean age was around 45 years for both men and women. Other characteristics of the patient population were that overweight had increased in 1995 and that the proportion of patients with primary school education decreased significantly during the period in both PHC and HHC. The proportion of patients who reported ill health was greater in HHC than in PHC, but the proportions did not change during the period.

In 1991 the proportion of patients who received advice about exercise and eating habits was about $17 \%$ both in HHC and in PHC (Table 2). There was a significant increase in advice given in HHC in 1995 compared with 1991, but this was not the case in PHC. The significant difference between PHC and HHC with respect to the change between 1991 and 1995 is indicated by the non-overlapping confidence intervals (CI) for the odds ratios (OR).

Overweight patients received more advice than normal-weight or underweight patients in both HHC and PHC (Table 2). For overweight patients

Table I. Background characteristics of the patient population

\begin{tabular}{lccl}
\hline & $199 \mid$ & 1995 & $p$ \\
\hline PHC (n) & 2203 & 1578 & \\
Age (years) & & & \\
Female (\%) & $45 \pm 16$ & $45 \pm 16$ & $\mathrm{~ns}$ \\
Poor health (\%) & 58 & 60 & $\mathrm{~ns}$ \\
Primary school (\%) & 12 & 12 & $\mathrm{~ns}$ \\
Overweight (\%) & 45 & 39 & $<0.001$ \\
Regular exercise (\%) & 41 & 48 & $<0.001$ \\
HHC (n) & 46 & 44 & $\mathrm{~ns}$ \\
Age (years) & & 1218 & \\
Female (\%) & 1286 & $44 \pm 16$ & $\mathrm{~ns}$ \\
Poor health (\%) & $45 \pm 16$ & 56 & $\mathrm{~ns}$ \\
Primary school (\%) & 56 & 17 & $\mathrm{~ns}$ \\
Overweight (\%) & 18 & 37 & $<0.001$ \\
Regular exercise (\%) & 45 & 46 & 0.007 \\
\hline
\end{tabular}

PHC: primary health care; HHC: hospital health care.

a Mean \pm SD. 
Table 2. Percentage of patients who received advice from the doctor about exercise and/or eating habits: odds ratio (OR) test over time

\begin{tabular}{|c|c|c|c|c|c|c|c|}
\hline All & 16.7 & 15.1 & 0.89 & $(0.74-1.06)$ & ns & 2203 & 1578 \\
\hline Normal + underweight & 13.3 & 11.9 & 0.88 & $(0.67-1.15)$ & ns & 1266 & 800 \\
\hline Overweight & 21.4 & 18.6 & 0.84 & $(0.66-1.07)$ & ns & 937 & 778 \\
\hline \multicolumn{8}{|l|}{ Both genders } \\
\hline Male & 26.3 & 24.1 & 0.89 & $(0.63-1.25)$ & ns & 424 & 333 \\
\hline Female & 17.4 & 14.5 & 0.81 & $(0.57-1.15)$ & ns & 513 & 445 \\
\hline \multicolumn{8}{|l|}{$\mathrm{HHC}$} \\
\hline Female & 12.6 & 16.3 & 1.35 & $(0.91-2.01)$ & ns & 427 & 351 \\
\hline Overweight & 18.9 & 27.8 & 1.65 & $(1.24-2.20)$ & $<0.001$ & 539 & 574 \\
\hline \multicolumn{8}{|l|}{ Both genders } \\
\hline Male & 25.3 & 37.8 & 1.79 & $(1.21-2.66)$ & 0.004 & 251 & 249 \\
\hline Female & 13.5 & 20.2 & 1.63 & $(1.05-2.52)$ & 0.036 & 288 & 325 \\
\hline
\end{tabular}

PHC: primary health care; HHC: hospital health care; $95 \% \mathrm{Cl}: 95 \%$ confidence interval.

Relative weight is dichotomized and overweight is classified here as a body mass index (BMI) greater than 25 for men and a BMI greater than 24 for women. All $\chi^{2}$ probabilities are two-sided. The population is standardized for age but not for gender in relation to the 1994 national population census in Sweden. Ten-year classes have been used for standardization.

there was a difference in the time trend of doctors' advice between PHC and HHC. In PHC about $20 \%$ of the overweight patients received advice in 1991 and 1995, while in HHC there was an increase from 19 to $28 \%$. There was no indication that the patients who were overweight in HHC had a higher BMI than the patients in PHC. The average BMI was 27.7 for the overweight patients in both PHC and HHC. Of the overweight patients in $\mathrm{HHC}$ in $1995,38 \%$ of the males and $20 \%$ of the females received advice.

It was more common for overweight males than for overweight females to have received advice at their last visit to a doctor (Table 2). In a multiple logistic regression analysis of 1995 data, background factors did not alter the gender difference regarding advice in PHC and HHC (Table 3). In PHC, patients with ill health and patients who were older received significantly more advice. Lifestyle factors such as exercise, smoking and alcohol consumption were not significantly related to this type of advice in PHC. Patients using heart medicine and medicine for high blood pressure did not receive more advice in PHC. In HHC the one significant factor besides gender that was related to receiving advice was heart medicine consumption.

The patients who received advice about diet changed their eating habits for the better. Among patients who received no advice, about $20 \%$ had improved their eating habits within the past year, while this figure was $43 \%$ for those who received advice about diet. Many of those who improved their eating habits reported that they consumed more vegetables, fruit and fibre, and less fat and fewer sweets than before.

\section{Discussion}

With what degree of confidence does this study reflect the amount of advice given concerning healthy lifestyles? As expected, the study shows that the overweight and obese groups received more advice about exercise and diet than patients of normal weight.

One restriction in the study concerns the aspect of recall. Since the encounter could have occurred up to 12 months previously, any advice given by the doctor could have been forgotten. Recall bias is expected to be of the same magnitude for both years, so the trend analysis for the two years is not 
Table 3. Multiple logistic regression analysis of odds ratios (OR) of gender and other patient characteristics as determinants for doctors' advice about exercise and eating habits to overweight patients (1995)

\begin{tabular}{|c|c|c|c|c|c|c|}
\hline Factor & OR & $95 \% \mathrm{Cl}$ & $p$ & OR & $95 \% \mathrm{Cl}$ & $p$ \\
\hline Gender (female/male) & 0.48 & $(0.32-0.73)$ & $<0.001$ & 0.41 & $(0.27-0.62)$ & $<0.001$ \\
\hline Age (per year) & 1.02 & $(1.00-1.03)$ & 0.059 & 0.99 & $(0.98-1.01)$ & ns \\
\hline Education (university or secondary school/primary school) & 0.85 & $(0.53-1.36)$ & ns & 0.73 & $(0.47-1.13)$ & ns \\
\hline Blood pressure medicine (yes/no) & 1.51 & $(0.93-2.46)$ & 0.100 & 1.26 & $(0.73-2.15)$ & ns \\
\hline BMI category (obese/overweight) & 1.37 & $(0.87-2.14)$ & ns & 1.26 & $(0.79-2.00)$ & ns \\
\hline Regular exercise (yes/no) & 1.04 & $(0.68-1.57)$ & ns & 1.16 & $(0.77-1.76)$ & ns \\
\hline Current smoker (yes/no) & 0.98 & $(0.58-1.65)$ & ns & 1.34 & $(0.82-2.17)$ & ns \\
\hline Alcohol consumption (high/normal or none) & 1.07 & $(0.66-1.73)$ & ns & 1.03 & $(0.64-1.64)$ & ns \\
\hline
\end{tabular}

PHC: primary health care; HHC: hospital health care; 95\% Cl: 95\% confidence interval; BMl: body mass index.

affected. However, the participation rate was just below $70 \%$, so that about $30 \%$ of the respondents were not covered by the study. The loss of respondents in this type of population-based study is known to be systematic. Single people and young people, especially males, do not respond to the same extent as those who are married and those who are older (13). The effect that this could have on the prevalence of advice is uncertain. For selfreported overweight and obesity, however, a considerable underestimation has been found in studies using this type of mail-distributed questionnaire (14). It has been found that self-reports of weight are too low and that self-reports of height are too high, which results in systematically lower BMI values $(15,16)$.

It is difficult to estimate the extent to which the results of this study can be generalized, even if the sample could be considered to be representative of the population. It was not possible to discover any changes in the local setting or in organizational factors during the study period that might have influenced the results other than an increased continuity in terms of consultations with doctors (17). It was also beyond the scope of this study to evaluate any general differences in practice between general practitioners (GPs) and specialists. It is nevertheless the case that in Sweden, PHC has an explicit responsibility for health promotion.

The finding that male patients received advice to a greater extent than female patients, even when obesity and health status were controlled for, might be explained by the fact that being male is in itself generally considered to be a risk factor. However, in a recent Swedish study overweight was shown to be a stronger risk factor in females than in males for mortality due to coronary heart disease (18). The findings from that study suggest that the increased mortality risk from overweight could very well have been underestimated for women. Traditionally, women have healthier lifestyles than men (12), and this might influence the amount of advice that is given. In the present study, however, the gender difference in doctors' advice remained after adjustments for self-assessed alcohol consumption, smoking and exercise.

During the period of study, doctors in HHC gave advice about healthy lifestyles to an increased number of patients, while the number of patients that received advice in PHC remained constant. These findings cannot be explained by any change in the patient population, or by a difference between doctors in primary care and those in hospital care concerning the types of patient groups that receive the most advice. However, there are more ill patients in HHC than in PHC and this can to a certain extent explain the more frequent advice given in HHC.

The physician might very well develop insight regarding those patients who can gain the most from a discussion on healthy lifestyles. The results from this study support such a selective process by doctors, since overweight patients and ill patients or patients on medication received the greatest amount of advice. Silagy et al. (19) reported results from an English population, where obese patients, physically inactive patients and patients with cardiovascular disease, respectively, received more advice from GPs about exercise and nutrition than patient groups with normal weight, patients who 
were physically active and patients with no history of cardiovascular disease. That overweight patients and ill patients received more advice than other groups indicates that the advice could be considered as treatment rather than prevention.

It is not easy to estimate the amount of advice that is a satisfactory level but the results suggest that there may be more room for doctors' advice to the overweight patients. The low frequency of advice given to female patients and the lack of increase in PHC may be of concern.

\section{Acknowledgements}

I am very grateful to Jane Wigertz, MSc, for linguistic assistance. The County Council of Östergötland generously provided the data used in this study.

\section{References}

1. Sjöström LV: Morbidity of severely obese subjects. Am J Clin Nutr 1992;55:508-15.

2. Rössner S. Obesity: an endemic disease. (Fetma en folksjukdom). Läkartidningen 1996;93:19-22. (In Swedish.)

3. Jung RT: Obesity as a disease. Br Med Bull 1997; 53:307-21.

4. Sullivan M et al. [Au: Please list first 6 authors?]Swedish obese subjects (SOS) - an intervention study of obesity. Baseline evaluation of health and psychosocial functioning in the first 1743 subjects examined. Int J Obes Relat Metab Disord 1993;17:503-12.

5. Gorksy RD, Pamuk E, Williamson DF, Shaffer PA, Koplan JP: The 25-year health care costs of women who remain overweight after 40 years of age. Am J Prev Med 1996;12:388-94.

6. Sjöström L, Narbro K, Sjöström D. Costs and benefit when treating obesity. Int $\mathbf{J}$ Obes Relat Metab Disord 1995; (Suppl 6): 9-12

7. Seidell JC, Verschuren WMM, Kromhout D: Prevalence and trends of obesity in the Netherlands 19871991. Int J Obes 1995;19:924-7.

8. Kukowska-Wolk A, Bergström R: Trends in body mass index and prevalence of obesity in Swedish women 198089. J Epidemiol Community Health 1993;47:195-9.
9. Lissner L, Johansson S-E, Qvist J, Rössner S, Wolk A: Social mapping of the obesity epidemic in Sweden. Int J Obes 2000;24:801-5.

10. Kreuter MW, Scharff DP, Brennan LK, Lukwago SN: Physician recommendations for diet and physical activity. Prev Med 1997;26:825-33.

11. Himmelmann L, Weinhall L. Doctors' work with prevention: important but difficult. (Preventivt läkararbete viktigt men vanskligt). Läkartidningen 1996;93:694-9. (In Swedish.)

12. Socialstyrelsen (National Board of Health and Welfare). Folkhälsorapport 1997. Socialstyrelsen, Stockholm 1997. (SoS-rapport 1997: 18). (In Swedish.)

13. Jacobsen BK, Thelle DS: The Tromsø heart study: responders and non-responders to a health questionnaire, do they differ? Scand J Soc Med 1988;16:101-4.

14. Nieto-Garcia FJ, Bush TL, Keyl PM: Body mass definition of obesity: sensitivity and specificity using selfreported weight and height. Epidemiology 1990;1: 46-52.

15. Stewart AW, Jackson RT, Ford MA, Beaglehole R: Underestimation of relative weight by use of self-reported height and weight. Am J Epidemiol 1987;125: 122-6.

16. Boström G, Diderichsen F: Socioeconomic differentials in misclassification of height, weight and body mass index based on questionnaire data. Int $\mathbf{J}$ Epidemiol 1997;26:860-6.

17. Rahmqvist M, Bäckman K. People's experiences with primary care, hospital care and dental care in the County of Östergötland. (Östgötarnas erfarenheter av primärvård, sjukhusvård och tandvård). Linköping University. CMT Report 1996: 3. (In Swedish.)

18. Qvist J, Johansson SE, Johansson LM: Multivariate analyses of mortality from coronary heart disease due to biological and behavioural factors. Scand J Soc Med 1996;24:67-76.

19. Silagy C, Muir J, Coulter A, Thorogood M, Yudkin P, Roe L: Lifestyle advice in general practice: rates recalled by patients. Br Med J 1992;305:871-4.

\footnotetext{
Mikael Rahmqvist

Center for Medical Technology Assessment (CMT),

Faculty of Health Sciences, Linköping University,

SE-58| 83 Linköping, Sweden.

E-mail: mikra@cmt.liu.se
} 